\title{
Population status, habitat dependence, and reproductive ecology of Bahama Orioles: a critically endangered synanthropic species
}

\author{
Melissa R. Price, ${ }^{1}$ Valerie A. Lee, and William K. Hayes
}

Loma Linda University, Loma Linda, California 92354, USA

Received 20 April 2011; accepted 29 July 2011

\begin{abstract}
Recent elevation of critically endangered Bahama Orioles (Icterus northropi) to species status prompted us to evaluate their population status, habitat use, and breeding ecology. From surveys, we estimated that at least 141 to 254 individuals remain globally, with 90 to 162, 24 to 44, and 27 to 48 individuals remaining on North Andros Island, Mangrove Cay, and South Andros Island, The Bahamas, respectively. Orioles were observed nesting exclusively in anthropogenic habitat (residential and agricultural land), but home ranges also included nearby pine forest and coppice (dry broadleaf forest). Most nests (40 of 46, or 87\%) were in nonnative coconut palm (Cocos nucifera), with native Sabal palmetto and Thrinax morrisii, and an introduced Brassaia actinophylla also used. Trees selected by orioles for nesting were significantly taller, less likely to have shrubs underneath, further from cover, and had more palm trees nearby than randomly selected palm trees. Three of eight nests with known contents were parasitized by Shiny Cowbirds (Molothrus bonariensis). Lethal yellowing disease recently devastated coconut palms and reduced the number of orioles on North Andros, but palms on Mangrove Cay and South Andros remain healthy. The juxtaposition of anthropogenic habitat to suitable native habitats may be more important than any single factor for Bahama Orioles, especially for breeding adults and fledged young. Conservation of coppice habitat, at high risk for agricultural and residential development, is crucial for survival of this critically endangered synanthropic species.
\end{abstract}

RESUMEN. Estatus de la población, dependencia del hábitat y ecología reproductiva de Icterus nortbropi: especies sinantrópica críticamente amenazada

El reciente reconocimiento como especies de Icterus northropi, el cual se encuentra en estado crítico de amenaza, nos llevó a evaluar, rapidamente, su estatus poblacional, uso de hábitat y ecología reproductiva. Utilizando censos, determinamos que quedaban de 141 a 254 individuos, con 90 a 162 en Andros del Norte, 24 a 44 en Cayo Manglar, y de 27 a 48 en Andros del Sur, Las Bahamas, respectivamente. Las aves fueron observadas anidando exclusivamente en hábitats antropogénicos (tierras agrícolas y áreas residenciales), pero el ámbito hogareño incluye bosques de pino (adyacentes) y bosque seco de hoja ancha. La mayoría de los nidos (40 de 46 o el 87\%) fueron encontrados en Palmas de Coco (Cocos nucifera), el cual no es nativo, utilizándose además especies nativas como Sabal palmetto y Thrinax morrisii y exóticos como Brassaia actinophylla. Los árboles seleccionados para anidar, fueron significativamente más altos, menos propensos a tener arbustos bajo estos, más lejos de cobertura y tenían más palmas en sus alrededores que árboles seleccionados al azar para anidar. Tres de ocho nidos, con contenido conocido fueron parasitados por el Tordo (Molothrus bonariensis). La enfermedad letal para las palmas de coco (yellowing disease), desbasto, recientemente, al coco y redujo el número de orioles en Andros del Norte, aunque las palmas se mantuvieron saludables en Cayo Manglar y Andros del Sur. La yuxtaposición de hábitat antropogénico y hábitat nativo adecuado, pudiera ser de mayor importancia que cualquier otro factor individual para el oriol de las Bahamas, especialmente para adultos reproductivos y volantones jóvenes. La conservación de bosque seco de hoja ancha, que está en alto riesgo para el uso agrícola y el desarrollo urbano, es crucial para la sobrevivencia de esta especie sinantrópica críticamente amenazada.

Key words: breeding behavior, brood parasitism, lethal yellowing, nest-site selection, Shiny Cowbird

Synanthropic species cohabit with humans and benefit from anthropogenic landscapes. Examples of highly endangered synanthropic species are exceptionally scarce, with only two species heretofore recognized among birdsSociable Lapwings (Vanellus gregarious; Kamp 2009) and Tuamotu Kingfishers (Todiramphus

\footnotetext{
${ }^{1}$ Corresponding author. Email: mrprice@llu.edu
}

gambieri gertrudae; Coulombe et al. 2011). Although saving synanthropic species seems intuitively straightforward, they can present unique challenges for conservation management because of potentially rapid cultural and evolutionary changes associated with landscape modification (Johnston 2001, Boardman 2006), reduced food availability (Tallamy 2004), other anthropogenic threats that counter the benefits of synanthropy (e.g., pesticide use, vehicle and 
window collisions, introduced predators), and partial continued dependence on natural habitats. Here, we present the highly unusual case of a critically endangered synanthropic species whose conservation is further complicated because it is an island endemic.

Oceanic islands present opportunities to test and implement management solutions in defined areas at high risk for species loss (Paulay 1994, Şekercioğlu et al. 2004). Extinction rates in the Caribbean islands, a biodiversity hotspot (Myers et al. 2000), have increased due to climatic changes and human influence (Woods and Sergile 2001, Steadman 2006, Ricklefs and Bermingham 2008). For example, $75 \%$ of West Indian parrots and macaws, 10 avian insectivores, and 27 bats have become extinct, and many more taxa are now threatened (Woods and Sergile 2001). Efforts to protect, manage, and preserve the remaining taxa are often hindered by limited knowledge of their natural history, lack of financial and educational resources, and a diversity of independently governing bodies (Ricklefs and Bermingham 2008). Basic research identifying high-quality habitats for all life history stages is needed to implement effective management solutions for many of the remaining endangered species (Donovan et al. 2002).

As one of the few birds endemic to The Bahamas, Bahama Orioles (Icterus northropi), recently given species status (American Ornithologists' Union 2010), are also one of the world's rarest species. After disappearing from Abaco Island, The Bahamas, in the 1990s, these orioles are currently only found on Andros. Baltz (1997) suggested that fewer than 300 individuals persisted, with populations largely confined to townships and agricultural areas along the coast where introduced coconut palm (Cocos nucifera) abounds (Allen 1890, Baltz 1997). This number, if confirmed, may be unsustainable given recent devastation of the oriole's favored coconut palm nesting habitat by lethal yellowing disease (Currie et al. 2005), loss of coppice (dry broadleaf forest) to farming and coastal development (Wunderle and Waide 1993), and the recent arrival of Shiny Cowbirds (Molothrus bonariensis; Baltz 1995, 1996), a brood parasite that favors this host (Wiley 1985). Baltz (1997), Jaramillo and Burke (1999), and Garrido et al. (2005) summarized the scant information available on the reproduction of Bahama Orioles.
Given the need for additional information about the status and ecology of Bahama Orioles, our objectives were to: (1) determine the relative population densities of Bahama Orioles in each of three primary habitats and estimate global population size, (2) examine the breeding ecology of Bahama Orioles, with emphases on nest attributes, nest-site selection, and the provisioning of nestlings, and (3) assess the potential impacts of Shiny Cowbirds and lethal yellowing on the reproductive success and local population density of the oriole. Collectively, our results should provide information needed for developing a sound management plan for this critically endangered synanthropic species.

\section{METHODS}

Study area and observational effort. The three major islands collectively referred to as Andros, The Bahamas, include North Andros (NA, $3600 \mathrm{~km}^{2}$ ), Mangrove Cay (MC, $200 \mathrm{~km}^{2}$ ), South Andros (SA, $\left.800 \mathrm{~km}^{2}\right)$, and a number of small cays. These islands, separated by channels 1 to $5 \mathrm{~km}$ wide, are dominated on the eastern portion by extensive Caribbean pine (Pinus caribaea) forest, interspersed with patches of coppice on low ridges. Mangrove, associated with vast tidal wetlands, dominates the western half of the islands. The pine forest was heavily logged in the mid-1900s (Myers et al. 2004), and degraded logging roads provide the only ground access to the interior. Pine trees in the secondary forest are slender and closely spaced, with an understory of poisonwood (Metopium toxiferum) and palmetto, fern, or shrub (Currie et al. 2005). Townships are spread along a single highway running north to south along the east coasts of NA, SA, and MC.

Total field time devoted to searching for and observing orioles was $\sim 770 \mathrm{~h}(72,158$, and $336 \mathrm{~h}$ on NA in 2005, 2007, and 2009, respectively; 14 and $81 \mathrm{~h}$ on MC in 2009 and 2010, respectively; 28 and $81 \mathrm{~h}$ on SA in 2009 and 2010, respectively). Total time in direct observation of orioles was $\sim 243 \mathrm{~h}$ (100 h NA, $65 \mathrm{~h} \mathrm{MC}$, and $78 \mathrm{~h} \mathrm{SA}$ ).

Population surveys. To evaluate population densities in the three primary habitats, we conducted line transect surveys from 5 to 18 July 2005 (late in the oriole breeding season) on NA following methods similar to 
Hayes et al. (2004). We walked individually or in pairs at $\sim 1 \mathrm{~km} / \mathrm{h}$, surveying 33 transects totaling $19.5 \mathrm{~km}$, with $9.8 \mathrm{~km}$ in coppice, $2.4 \mathrm{~km}$ in pine forest, and $7.3 \mathrm{~km}$ in anthropogenic habitat. We recorded all birds observed or heard to compare the relative and habitat-specific abundance of orioles and cowbirds.

Given the low number of orioles encountered during the 2005 habitat density surveys, we attempted to thoroughly census all known breeding habitat on North Andros, Mangrove Cay, and South Andros in 2009. Because orioles nest primarily in and adjacent to anthropogenic habitat, we focused our efforts there and surveyed $\sim 90 \%$ of all townships on NA, $95 \%$ on $\mathrm{MC}$, and $95 \%$ on SA. Searches were conducted at the peak of the breeding season while studying oriole reproduction on NA, MC, and SA from 29 March to 30 May 2009. Traveling at a slow pace through townships and agricultural habitat where coconut palms were present, we searched for orioles using playback, audio, and visual searches (Baltz 1997). This method was effective because the birds are large, colorful, and usually sing from exposed perches (Baltz 1997), and nesting habitat (palm trees) was within $30 \mathrm{~m}$ of roads. Nests were easily located on the underside of palm fronds during visual searches. Searches were also conducted in pine forest and coppice habitats, both with and without endemic palms, away from developed habitat, but few orioles $(N=3)$ were observed in these areas during the peak months of the breeding season. Because most orioles were unmarked, we avoided pseudoreplication of counts on subsequent days in repeatedly surveyed areas by only counting additional orioles if multiple birds were observed at the same time. We computed the approximate area for each township surveyed using ArcGIS (ESRI, Redlands, CA) and calculated oriole density (total birds discovered per unit area) for each township.

Behavioral observations. We conducted continuous observations of oriole breeding pairs up to $2 \mathrm{~h}$, every 1 to $4 \mathrm{~d}$. We noted time, habitat, behavior, and age of bird as hatchyear (HY), second-year (SY), or after-secondyear (ASY) plumage (Jaramillo and Burke 1999). Because Bahama Orioles are monomorphic and monochromatic (Garrido et al. 2005), sex could not be determined visually. We determined clutch sizes of accessible nests using a handbuilt pole-mounted infrared video camera when adults were absent or by observing nestlings directly. We also observed adult provisioning of nestlings to quantify intervals between visits and duration of visits.

Nest-site selection. We used a paired design to compare nest site and corresponding randomly located palm locations within $100 \mathrm{~m}$ of nest trees to identify possible nestsite selection factors (Beck and George 2000). Only palms were evaluated because orioles nested almost exclusively in palm trees. For each nest site, we measured microhabitat- (nest tree), mesohabitat- (0.04-ha circular plots), and macrohabitat- (beyond mesohabitat) scale attributes. These three sets of attributes were used to identify the spatial scale at which birds potentially select nesting locations. We measured the same attributes of four randomly selected palms within $100 \mathrm{~m}$ of nest trees by generating four random directions and distances between 25 to $100 \mathrm{~m}$, and choosing the individual palm tree ( $>2 \mathrm{~m}$ height) nearest each randomly generated location. Mean values of the four randomly selected palms were compared to nest-site values. If multiple nests were present in the same territory, mean values were used to avoid pseudoreplication. Territories were easily identified because, due to low oriole density, most nest sites were not adjacent to one another and only one pair was present in the nesting area. In one case where nests of two oriole pairs were within $75 \mathrm{~m}$ of one another, territories were delineated by observing oriole pair defensive interactions. Nest height, frond layer where nests were located, and compass direction of nests relative to trunks were also noted.

\section{Microhabitat-scale (tree) attributes.}

At each nest site and randomly generated location, we recorded the tree species, height of the bole of the tree, diameter at breast height (dbh), and distance to nearest cover $>1 \mathrm{~m}$ in height. Because height was determined by measuring from the trunk base to the first frond attachment point (or to the top of the trunk for dead palms), nest height was sometimes greater than tree height. We evaluated the health of trees using the following scale, with $0=$ no fronds remaining on trunk, $1=$ all fronds yellow or brown, $2=>50 \%$ fronds yellow, $3=<50 \%$ fronds yellow, and $4=$ no evidence of lethal yellowing. 


\section{Mesohabitat attributes.}

Within 0.04-ha circular plots (11.4-m radius from palm at center), we recorded the species, health, and height of each palm tree $>1 \mathrm{~m}$ in height. Percent cover of shrub, bare ground, and litter were visually estimated within plots.

\section{Macrohabitat attributes.}

From the center of each plot, we measured distances to the nearest road (as a proxy for human disturbance), nearest pine forest, and nearest coppice.

Potential impacts of Shiny Cowbirds and lethal yellowing. We determined incidence of Shiny Cowbird brood parasitism via direct observation of accessible nests. We evaluated palm health using the aforementioned scale by conducting line transects of palms, recording those $>1 \mathrm{~m}$ in height within $30 \mathrm{~m}$ of transects. As coconut and other nonnative palms are primarily present in areas where people have planted them, surveys were restricted to townships. Length of transects $(0.3-0.7 \mathrm{~km})$ varied depending on size of the township and density of coconut palms. One transect was conducted per township in areas of highest coconut palm density. Palm health was evaluated at limited locations on NA in $2005(N=1)$ and 2007 $(N=9)$, and more extensively on $\mathrm{NA}(N=9)$, $\mathrm{MC}(N=5)$, and SA $(N=7)$ in 2009 during the same dates as the other oriole research. The number of orioles and nests observed while conducting palm surveys was noted.

Statistical analyses. We used both parametric ( $t$-tests, Pearson's correlation, logistic regression, and analysis of variance [ANOVA] with Tukey's HSD post-hoc comparisons) and nonparametric (Chi-square and Friedman's ANOVA) tests, depending on the nature of the dependent measure and whether assumptions were met (Zar 1996, Mertler and Vannatta 2004). We did not arcsin-transform percentage data because doing so did not improve normality. We also computed effect sizes, which are independent of sample size (in contrast to statistical significance), and more readily compared among different data sets and studies. These included Cohen's $d$ using pooled standard deviation for pairwise comparisons $(\sim 0.5$ considered moderate and $\geq 0.8$ large), Phi $(\varphi)$ for $2 \times 2$ and Cramer's $V$ for larger contingency tables ( $\sim 0.3$ deemed moderate and $\geq 0.5$ large), coefficients of determination $\left(r^{2}\right)$ and Nagelkerke
$R^{2}$ for correlations and logistic regression model fit, respectively $(\sim 0.09$ considered moderate and $\geq 0.25$ large), and log-odds ratios for logistic regression (with deviation from 1.0 indicating proportion of variance explained; Mertler and Vannatta 2004). The terms "moderate" and "large" are used subjectively following the guidelines of Cohen (1988). We employed Rayleigh's test of uniformity and a Watson-Williams test for circular data (Zar 1996).

We relied on binary logistic regression models to identify which scale (micro, meso, or macro) was most successful in discriminating nest trees from random trees. Because of sample size limitations, we used univariate analyses $(t$-tests and corresponding effect sizes; Table 1$)$ to identify three factors at each scale (macro, meso, and micro) that explained the most variance, and then used these in the full binary logistic regression models. Tolerance levels were checked to ensure none of the predictors within a given model covaried.

Statistical analyses were conducted using SPSS 17.0 (SPSS Inc., Chicago, IL) for most data, employing standard defaults for full logistic regression models, and alpha $=0.05$. We analyzed circular data using R 2.12.1 with the package Circular (Lund and Agostinelli 2011). Following Nakagawa (2004), we chose not to adjust alpha for multiple tests. Values are presented as means \pm SE.

\section{RESULTS}

Population densities and estimates. Distance transects late in the breeding season of 2005, following the fledging of most nests, revealed that Bahama Orioles on NA were most numerous in coppice $(5.6 \pm 4.4 / \mathrm{km})$, followed by anthropogenic habitat $(1.2 \pm 0.6 / \mathrm{km})$ during this stage of breeding. Although we did not detect orioles in pine forest, they were occasionally observed in this habitat during subsequent work. Shiny Cowbirds were scarce in anthropogenic habitat $(0.3 \pm 0.2 / \mathrm{km})$ and pine forest $(0.2 \pm 0.2 / \mathrm{km})$, and absent from coppice. The comparatively low cowbird density (ratio $=$ 0.17 per oriole) was confirmed by informal observations in subsequent years. Because transects with zero counts limited the statistical power of comparisons, we could not identify possible habitat preferences of either species. 
Table 1. Potential nest-site selection by Bahama Orioles, with comparisons of nest trees and random trees $(\bar{\chi} \pm \mathrm{SE})$ at micro- $(N=31)$, meso- $(N=20-31)$, and macrohabitat $(N=23-31)$ levels via paired $t$-tests (for quantitative variables) and Chi-square tests (for categorical variables).

\begin{tabular}{lccccc}
\hline Nest-site scale & Nest & Random & & & \\
& $\bar{\chi} \pm \mathrm{SE}$ & $\bar{\chi} \pm \mathrm{SE}$ & Test statistic & $P$ & Effect size \\
\hline Microhabitat variables & & & & & \\
$\quad$ Tree height (m) & $6.1 \pm 0.5$ & $4.9 \pm 0.3$ & $t_{30}=2.8$ & 0.008 & $d=0.56$ \\
Tree health (0-4) & $2.6 \pm 0.1$ & $2.5 \pm 0.1$ & $t_{30}=1.6$ & 0.13 & $d=0.28$ \\
Tree dbh (cm) & $25.5 \pm 0.7$ & $25.5 \pm 0.5$ & $t_{23}=0.02$ & 0.99 & $d=0.00$ \\
Distance from tree to cover (m) & $6.9 \pm 0.7$ & $5.3 \pm 0.4$ & $t_{30}=2.5$ & 0.02 & $d=0.53$ \\
Tree species (number) & & & $\chi_{3}^{2}=1.1$ & 0.79 & $V=0.06$ \\
Cocos nucifera & $40(87.0 \%)$ & $194(91.5 \%)$ & & & \\
Sabal palmetto & $2(4.3 \%)$ & $6(2.8 \%)$ & & & \\
Thrinax morrisii & $3(6.5 \%)$ & $8(3.8 \%)$ & & & \\
Brassaia actinophylla & $1(2.2 \%)$ & $4(1.9 \%)$ & & & \\
Mesohabitat variables & & & & & \\
Litter (\%) & $6.9 \pm 2.8$ & $10.5 \pm 2.7$ & $t_{30}=1.2$ & 0.25 & $d=0.24$ \\
Bare (\%) & $83.9 \pm 3.8$ & $71.6 \pm 3.6$ & $t_{30}=2.4$ & 0.021 & $d=0.61$ \\
Shrub (\%) & $8.3 \pm 1.9$ & $18.0 \pm 2.3$ & $t_{30}=3.3$ & 0.002 & $d=0.86$ \\
No. palms in meso-plot & $1.3 \pm 0.2$ & $1.0 \pm 0.1$ & $t_{30}=1.9$ & 0.064 & $d=0.28$ \\
Height of palms in meso-plot (m) & $5.5 \pm 0.5$ & $4.2 \pm 0.4$ & $t_{30}=3.0$ & 0.007 & $d=0.71$ \\
Health of palms in meso-plot (0-4) & $3.4 \pm 0.2$ & $3.4 \pm 0.1$ & $t_{30}=0.3$ & 0.78 & $d=0.10$ \\
Macrohabitat variables & & & & & \\
$\quad$ Distance to road (m) & $14.2 \pm 3.0$ & $16.6 \pm 2.5$ & $t_{30}=1.2$ & 0.25 & $d=0.16$ \\
Distance to coppice (m) & $48.8 \pm 9.3$ & $51.6 \pm 9.7$ & $t_{30}=0.4$ & 0.71 & $d=0.02$ \\
Distance to pine forest (m) & $183.9 \pm 33.6$ & $184.7 \pm 34.2$ & $t_{23}=0.2$ & 0.85 & $d=0.00$ \\
\hline
\end{tabular}

${ }^{\mathrm{a}} 0=$ no fronds remaining on trunk, $1=$ all fronds yellow or brown, $2=$ greater than $50 \%$ fronds yellow, $3=$ less than $50 \%$ fronds yellow, and $4=$ no evidence of lethal yellowing

During more extensive field work and intensive searches of most of the known breeding habitat during the peak of the breeding season (April-May) of 2009, we observed 81 orioles on NA (48 ASY, $21 \mathrm{SY}$, and 12 unknown; 29 observed pairs), 22 on MC (19 ASY and 3 SY; 10 observed pairs), and 24 on SA (19 ASY, 3 SY, and 2 unknown; 8 observed pairs). Surveys in Caribbean pine forest habitats on Grand Bahama by Lloyd and Slater (2011) resulted in $50 \%$ to $90 \%$ detectability for most bird species during single transects. Our surveys in 2009 , focused on orioles in known breeding habitat, were much more comprehensive than those of Lloyd and Slater (2011), as they involved repeated surveys of the same areas over multiple days, likely resulting in detectability at the higher end of this range. Based on $50 \%$ to $90 \%$ detectability of surveyed areas, we estimated that at least 90 to 162,24 to 44 , and 27 to 48 Bahama Orioles remain on NA, MC, and SA, respectively. In sum, we estimated the global population at 141 to 254 individuals (but see Discussion).

Breeding and nesting. We observed orioles paired and duetting together as early as 30 March (2009), initiating incubation on 15 April (2009), and feeding nestlings as late as 8 August (2010; Rimstad, pers. comm.). From bouts of continuous observations of three focal pairs, only one individual per pair, assumed to be female as in other oriole species (Rising and Flood 1998, Rising and Williams 1999; but see Jaramillo and Burke 1999), constructed nests over a period of $\sim 1$ week. Mates attended their movements, often singing on nearby perches during this time. Nests were found only in residential and agricultural habitats where coconut palms were present, despite searches in pine and coppice habitat. A higher proportion of oriole pairs included a SY mate (50\% of 18 ) on NA than on MC and SA (7\% of 15, pooled; $\chi_{2}^{2}=7.3, P=0.007$, $\varphi=0.47)$. 
We found 37 nests built by 24 pairs on NA in 2009 ( $1-4$ nests/pair, mean $=1.5)$. In 2010, we found eight nests built by six pairs on MC and one nest on SA (1-2 nests/pair, mean = 1.3). At six sites, the same tree was used for multiple nests built in the same year by the same pair. Nearest-neighbor distances between nests (excluding distances between nests in the same territory) ranged from $75 \mathrm{~m}$ to $11.4 \mathrm{~km}$ (mean $=$ $1297 \pm 552 \mathrm{~m} ; N=24$ ) on NA and from 265 to $3591 \mathrm{~m}$ (mean $=2003 \pm 477 \mathrm{~m} ; N=6)$ on MC, with no difference between islands $\left(t_{1}=\right.$ $0.7, P=0.49$, Cohen's $d=0.33$ ). Mean nest height was $6.0 \pm 0.4 \mathrm{~m}($ range $=1.8-12.9 \mathrm{~m})$ in trees having a mean height of $6.1 \pm 0.5 \mathrm{~m}$ (range $=2.0-13.7 \mathrm{~m}$ ) and a mean health of $3.6 \pm 0.1$ (range $=3.0-4.0$ ). Nest orientation data for 2009 (NA) and 2010 (MC and SA) did not differ significantly (Watson-Williams test) and were combined. Nests were built with directional preference relative to trunks $(z=0.3$, $P=0.04, N=41)$, and were most often in the northwest quadrant (leeward side) of palm trees $\left(\right.$ mean orientation $\left.=307^{\circ}\right)$. Nests were more often built in the lowest layer of palm fronds $(96 \%)$ than in higher layers $\left(4 \% ; \chi_{2}^{2}=78.4\right.$, $P<0.001, N=45)$. Oriole nests in endemic Thrinax morissi and Sabalpalmetto $(N=5)$ were built in the retained dead layers of thatch under the crowns. One T. morissi contained three nests, two built in 2009 and one reportedly from 2008 (Smith, pers. comm.).

Nest-site selection. Microhabitat-scale model. Most nests (40 of 46 , or $87 \%$ ) were in coconut palms, with native $S$. palmetto $(N=$ 2) and T. morisii $(N=3)$ palms and an introduced Brassaia actinophylla tree $(N=1)$ also used. The proportion of tree species used did not differ from availability (Table 1). Nest trees were significantly taller $(P=0.008)$ and further from nearest cover $(P=0.02)$ than randomly selected trees, but were similar in girth (dbh) and health (Table 1). The logistic regression model, including the variables tree height, health, and distance to cover, significantly distinguished between nest and random trees $(P=0.009$; Table 2$)$. The model predicted nest $(58.1 \%)$ and random $(68.8 \%)$ trees with weak to moderate success $(63.5 \%$ overall). Tree height $(P=0.031)$ and distance to cover $(P=0.033)$ remained significant, with logodds ratios (exp[B] values, Table 2$)$ indicating a $27.6 \%$ increase in probability of tree use for nesting with each $1-\mathrm{m}$ increase in height, and a $17.4 \%$ increase with each $1-\mathrm{m}$ increase in distance to cover.

\section{Mesohabitat-scale model.}

Of the six mesohabitat-scale variables (Table 1$)$, palm tree height $(P=0.007)$ and proportion of bare ground $(P=0.020)$ in nest meso-plots were higher in nest plots than random plots, whereas a smaller proportion of ground was covered by shrubs $(P=0.002)$. The logistic regression model using three predictors (palm tree height, percent ground cover in shrubs, and number of palms; proportion of bare ground was omitted due to reciprocality with ground cover) provided strong discrimination between nest and random meso-plots $(P<$ 0.001; Table 2), and predicted nest (71.4\%) and random (80.8\%) meso-plots with high success (76.6\% overall). All three variables were significant, with log-odds ratios indicating a $46.1 \%$ increase in probability of nesting with each 1 - $\mathrm{m}$ increase in average height of palms, a $73.9 \%$ increase with each additional palm in the plot, and a $10.4 \%$ decrease with each $1 \%$ increase in shrubs.

\section{Macrohabitat-scale model.}

None of the three macrohabitat variables differed between nest and random sites (Table 1), as confirmed by logistic regression (Table 2), which yielded comparatively poor predictive success (nest trees, 56.5\%; random trees, $62.5 \%$; overall, $59.6 \%$ ).

Incubation, provisioning, fledging, and nest defense. Incubation lasted 12 to $14 \mathrm{~d}$ ( $N=4$ nests). Only one bird, presumably the females, appeared to incubate. Both parents, in contrast, brooded and fed nestlings, sometimes feeding nestlings simultaneously. Nests were covered, making it difficult to see food presented to nestlings, but parents were most often observed delivering insects, with berries and an occasional Anolis lizard also delivered. Mean feeding interval decreased from $12.0 \pm$ 2.5 min during the first six days after hatching to $10.7 \pm 8.6 \mathrm{~min}$ for days 7 to 10 posthatching, and to $7.8 \pm 1.7 \mathrm{~min}$ for days 11 to 14 posthatching ( $N=5,6$, and 5, respectively). Mean time at nests decreased from $3.5 \pm 1.2$ $\min$ to $1.4 \pm 0.6 \mathrm{~min}$, and to $1.0 \pm 0.3 \mathrm{~min}$ for the same periods $(N=5,6$, and 5 , respectively). 
Table 2. Results of logistic regression models for three scales of potential nest-site selection by Bahama Orioles, comparing nest sites (coded as zero) paired with random sites (coded as one). ${ }^{2}$

\begin{tabular}{lrrrrr}
\hline Predictors & B & SE & Wald & $P$ & $\operatorname{Exp}(\mathrm{B})$ \\
\hline Microhabitat model $(N=31)$ & & & & & \\
$\quad$ Height & -0.32 & 0.15 & 4.7 & 0.031 & 0.72 \\
$\quad$ Health & 0.70 & 0.65 & 1.2 & 0.28 & 2.01 \\
$\quad$ Distance to cover & -0.19 & 0.09 & 4.6 & 0.033 & 0.83 \\
Mesohabitat model $(N=21)$ & & & & & \\
$\quad$ Shrub ground cover (\%) & 0.10 & 0.04 & 5.5 & 0.020 & 1.10 \\
$\quad$ Number of meso-plot palms & -1.34 & 0.53 & 5.1 & 0.024 & 0.26 \\
$\quad$ Height of meso-plot palms $(\mathrm{m})$ & -0.62 & 0.25 & 6.4 & 0.011 & 0.54 \\
Macrohabitat model $(N=23)$ & & & & & \\
$\quad$ Distance to road $(\mathrm{m})$ & 0.01 & 0.02 & 0.2 & 0.67 & 1.01 \\
$\quad$ Distance to coppice $(\mathrm{m})$ & 0.00 & 0.01 & 0.01 & 0.92 & 1.00 \\
$\quad$ Distance to pine forest $(\mathrm{m})$ & 0.00 & 0.00 & 0.01 & 0.91 & 1.00 \\
\hline
\end{tabular}

${ }^{a}$ Microhabitat: $\chi_{3}^{2}=11.5, P=0.009,-2 \log$ likelihood $=75.2$, Nagelkerke $R^{2}=0.22,63.5 \%$ predicted correctly. Mesohabitat: $\chi_{23}=23.3, P<0.001,-2 \log$ likelihood $=41.3$, Nagelkerke $R^{2}=0.52,76.6 \%$ predicted correctly. Macrohabitat: $\chi_{3}^{2}=0.2, P=0.98,-2 \log$ likelihood $=64.9$, Nagelkerke $R^{2}=0.01$, $59.6 \%$ predicted correctly.

Using only nests where we had data for each age group, neither feeding interval (Friedman's ANOVA; $\chi_{2}^{2}=1.5, P=0.47, N=4$ ) nor parent time-at-nest (Friedman's ANOVA; $\chi_{2}^{2}=$ 2.8, $P=0.25, N=4$ ) differed among the three age classes, but sample sizes were small. Both parents removed fecal sacs of older ( $>5 \mathrm{~d})$, but not younger nestlings, and dropped them as they flew from nests. Both adults contributed to nest defense, flying aggressively toward and scolding birds of other species that perched in nest trees.

In July 2007, we observed an HY bird feed nestlings and being fed by an oriole in ASY plumage. This HY bird was able to fly to and from the nest, but often stayed in the nest for prolonged periods of time, perhaps assisting with brooding. Another ASY adult was in the area, but we could not confirm pair status.

Of six nests observed closely enough to determine success, all fledged from 2 to 4 young (mean $=2.5)$ at 12 to $14 \mathrm{~d}$ after hatching, and all within a 24-h period. In two fledging events witnessed, chicks flew to cover $<10 \mathrm{~m}$ from nests and were fed by parents for several hours before moving to nearby coppice, where they were observed being fed several days later.

Shiny Cowbird brood parasitism. Shiny Cowbirds parasitized two (28.6\%) of seven active nests with known contents. One nest fledged one cowbird and two oriole chicks; a second nest contained four cowbird eggs. Additionally, at least one abandoned nest contained a cowbird egg. Cowbirds may have contributed to some of the other nest failures observed because 39\% of 31 nest sites contained one or more abandoned nests in addition to the active nest. Cowbirds were observed cryptically watching within oriole territories $(N=2)$, flying into view during taped playback of a Bahama Oriole song $(N=1)$, and flying into the vicinity when orioles gave calls $(N=1)$.

Lethal yellowing impact. Analysis of 2009 data revealed differences among islands in palm tree health (one-way ANOVA; $F_{2,1054}=$ 251.0, $P<0.001, \eta^{2}=0.32$ ). Post-hoc tests suggested the lethal yellowing outbreak began in, and may presently be confined to, NA, where scores for palm health (mean $=2.1 \pm$ $0.1, N=365)$ were lower $(P<0.001)$ than on $\mathrm{MC}($ mean $=3.6 \pm 0.04, N=299)$ and SA $(3.7 \pm 0.03, N=393)$. Palm health was similar for $\mathrm{MC}$ and SA $(P=0.91)$. In Staniard Creek, NA, where the lethal yellowing outbreak appears to have originated, mean palm tree health decreased significantly from $1.54 \pm$ 0.07 in $2005(N=444)$ to $0.06 \pm 0.03$ in $2007(N=101)$ and $0.03 \pm 0.03$ in 2009 $\left(F_{2,608}=135.6, P<0.001, \eta^{2}=0.21, N=\right.$ 66), with $97 \%$ mortality. In 2009 , no orioles were observed where they had been present in previous years in Staniard Creek. Healthier palm communities were associated with higher oriole 


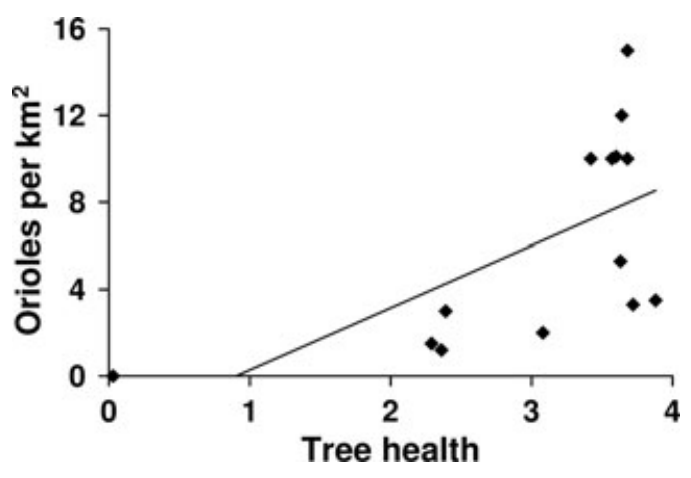

Fig. 1. Bahama Oriole density as a function of average palm tree health among 14 anthropogenic areas (townships and agricultural fields) on Andros Island, Bahamas $\left(r^{2}=0.38, P=0.019\right.$; data from 2009 surveys). Palm health during transects was scored on a scale from 0 (no fronds remaining) to 4 (no sign of disease). Oriole density decreased in areas where lethal yellowing negatively impacted the health of palm trees.

density (Pearson's $r^{2}=0.38, P=0.019, N=$ 14 townships; Fig. 1). In 2009, mean oriole density in NA townships was 2.2 orioles $/ \mathrm{km}^{2}$, compared to $11.8 / \mathrm{km}^{2}$ on $\mathrm{MC}$ and $6.7 / \mathrm{km}^{2}$ on SA. The Atlantic Undersea Test and Evaluation Center (AUTEC) on NA had a density of 10.0 orioles per $\mathrm{km}^{2}$, similar to densities on $\mathrm{MC}$ and SA, and had healthy palm trees due to regular maintenance by grounds crews and inoculation against lethal yellowing.

\section{DISCUSSION}

Island endemics often have contracted ranges and population sizes, leaving them vulnerable to changes associated with human arrival and influence, as well as stochastic events (Karels et al. 2008). Furthermore, small islands may lose species more quickly than large islands because of the greater scope of human influence per island area (Steadman 2006). Although we found that anthropogenic habitats appear to benefit Bahama Orioles during the breeding season, development on these Bahamian islands frequently occurs at the expense of coastal coppice (Maillis, pers. comm.), a habitat that appears to be particularly crucial for orioles after fledging and during the nonbreeding season. These factors may have contributed to the loss of Bahama Orioles from Abaco Island by the early 1990s (White 1998), an island smaller and more developed than Andros. Although Bahama Orioles may never have existed in large numbers (Baltz 1997), recent arrivals of the Shiny Cowbird and lethal yellowing disease pose novel threats to the small remaining population. Our results point to several solutions that may provide hope for this endangered bird.

Population densities and estimates. Our early breeding season surveys (2009) corresponded with previous observations by Baltz (1996, 1997), who found nesting orioles and cowbirds primarily in anthropogenic habitat. However, we frequently saw adult orioles foraging in nearby pine and, especially, coppice habitats. Later in the breeding season, after most nestlings had fledged, oriole density was highest in coppice habitat, as reflected in our 2005 habitat surveys. During winter surveys, Currie et al. (2005) detected orioles only in coppice and agricultural areas, and did not observe them in pine forest lacking a coppice understory. Collectively, these results suggest that anthropogenic habitat, although beneficial for nesting, is not sufficient to sustain oriole populations. Natural habitat, especially coppice, appears to be important year-round for Bahama Orioles.

Since the first observation of Shiny Cowbirds in the Bahamas on Andros Island (Baltz 1995), Shiny Cowbirds have been observed on Grand Bahama during the 2001, 2004, and 2009 Christmas Bird Counts (CBC), and on New Providence Island during the 2005 CBC (National Audubon Society 2010). In spite of their spread, the cowbird population does not appear to be increasing on Andros. Baltz (1997) found ratios of 0.33 and 0.29 cowbirds to orioles during breeding season surveys in 1995 and 1997, respectively, compared to our observation of 0.17 cowbirds to orioles in 2005. Shiny Cowbirds were detected during the 1995 CBC on NA, but not before or since, possibly indicating a migratory population (Baltz 1995). Currie et al. (2005) did not detect Shiny Cowbirds during winter surveys, so we are unable to compare their winter and breeding habitat use.

Our total population estimate for Bahama Orioles (141-254) corroborates a previous estimate of $~ 300$ individuals (Baltz 1997), and suggests these orioles are critically endangered by IUCN criteria ( $<250$ individuals globally, with decreasing numbers following extirpation on 
Abaco). Because our breeding season surveys and those of Baltz (1997) were confined to readily accessible habitat along the eastern portion of the islands, abundance may be higher if some orioles nest in the pine forest interior or in the less accessible western portion of the island (dominated by mangroves). Although rarely encountered in pine forest, scattered pairs may nest in the palm understory, or in patches of palms among the extensive mangrove flats. For example, orioles are still present near anthropogenic habitat on the west coast where Northrop observed them a century ago (Allen 1890), in Red Bays (this study), and at Flamingo Cay Resort near Wide Opening (Rimstad, pers. comm.). Smaller cays, such as Big Wood Cay $\left(40 \mathrm{~km}^{2}\right)$ just north of Mangrove Cay, may also support a few pairs.

The disparity in oriole densities on NA, $\mathrm{SA}$, and MC presumably reflects degradation of nesting habitat by lethal yellowing on NA or destruction of coppice for agricultural development, and presents some concern. Low densities may lead to decreased mate choice, loss of genetic diversity as a result of genetic drift, and increased inbreeding resulting in decreased heterozygosity (Frankham et al. 2002).

Breeding. Prior to the arrival of humans and the coconut palm, Bahama Orioles likely nested in endemic palms such as T. morisii and $S$. palmetto. We found that oriole nests in endemic palms were built in the dead layers of thatch under the crown of the palm that accumulates in the absence of fires. Forest fires occurred less often prior to the arrival of humans (Myers et al. 2004), allowing endemic palms to grow taller, as preferred by the orioles in our study. Today, many forested areas burn every 1 to 3 yr (Myers et al. 2004), which may limit palm availability in this habitat. Like other investigators (Allen 1890, Baltz 1997), we were unable, despite searches, to find nests in the pine forest habitat we were able to access. However, pine forest deeper inland, further from human influence and spared from frequent fires, may support a palm understory that provides suitable oriole nesting habitat. Additional study is needed to explore this difficult-to-access terrain.

In 2009, nine of 18 pairs on NA included at least one SY bird and, for two pairs, both individuals were SY birds, indicating that at least some SY males are breeding. This proportion is within the normal range for breeding SY males among oriole species (6-55\%; Rising and Flood
1998, Rising and Williams 1999, Flood 2002, Brush and Pleasants 2005, Werner et al. 2007). However, the high proportion of oriole pairs with a SY mate on NA compared to MC and SA suggests that oriole density on NA is functionally low, promoting breeding by younger birds.

Our observations augment prior anecdotal reports of breeding phenology (March-August), nest tree preference (palms), clutch size (2-4), incubation duration and time to fledging (12$14 \mathrm{~d}$ each), and nestling diet (fruit, insects, and lizards) of Bahama Orioles and other Greater Antillean oriole species (Baltz 1997, Rising and Flood 1998, Jaramillo and Burke 1999, Garrido et al. 2005). We observed both parents removing fecal sacs of chicks older than $5 \mathrm{~d}$, but not younger nestlings; sacs of younger chicks may be eaten, as reported for related species (Flood et al. 2002). Although other Greater Antillean orioles may breed year-round, there is no evidence of this for Bahama Orioles (Garrido et al. 2005). The preferred location of Bahama Oriole nests in the leeward (northwestern) side of trees is exhibited by some, but not all, populations of other oriole species (Schaefer 1976, Rising and Flood 1998). This preference may be beneficial given the primarily southeastern winds at this time of year on Andros Island.

Because coconut fronds remain on trees for only $2.5 \mathrm{yr}$, and the lowest fronds are oldest (Child 1974), nests built in the lowest frond layer are probably not available for reuse in successive years. However, fronds are retained in Thrinax and Sabal in the absence of fire (pers. obs.), so nests may accumulate in these species from year to year. Other oriole species occasionally reuse nests within the same season (Werner et al. 2007), but we did not observe such reuse in our study. All active nests appeared to have been built within the season based on the color of the fibers used to weave nests.

Typical of other tropical birds (Russell et al. 2004), oriole family groups often remain together until the next breeding season. We observed family groups foraging together as late as April $2009(N=1)$ and May $2010(N=2)$. During the peak breeding season (mid-May to early June), however, only paired or single birds were observed, suggesting that family groups do not remain together through the breeding season. An interesting derivative of delayed dispersal may be the occasional occurrence of a helper-at-the-nest when orioles double-brood. 
In July 2009, we observed a bird in HY plumage assisting in feeding chicks and receiving feedings from an oriole in ASY plumage. This is the first report to our knowledge of a helper-at-the-nest for any oriole species (Skutch 1996, Flood, pers. comm.; c.f. Hilton et al. 2005), and suggests double brooding, as occurs in some other oriole species (Jaramillo and Burke 1999, Hilton et al. 2005, Ligi and Omland 2007).

Nest-site selection. Bahama Orioles nested in significantly taller trees than randomly available palm trees, and preferred sites with less brush and taller palm trees within meso-plots. These preferences likely explain their use of introduced palm trees, which attain greater heights than native palms. Preference for less brush near nest trees could reflect selective pressure from biting insects (Lothrup et al. 2002; Darbro and Harrington 2007) and snake (Epicrates striatus fowleri; Wunderle et al. 2004) predators. Although most nests were in coconut palms, proportional use of this species did not differ from palm species available within $100 \mathrm{~m}$ of nest trees. However, the presence of coconut palms may be important at a larger scale (which we did not assess quantitatively) because we found no nests in areas lacking coconut palms.

Shiny Cowbird brood parasitism. The low density of Bahama Orioles is of concern given the presence of Shiny Cowbirds in the oriole's preferred breeding habitat. Although only two of seven active nests with known contents were parasitized in our study, Baltz $(1996,1997)$ found that four nests initiated later in the breeding season on North Andros were all parasitized. At least one abandoned nest in our study was parasitized, and cowbird activity may have contributed to the high number of nest sites with one or more abandoned nests (39\% of 31 nest sites). Intensive cowbird trapping programs have been successful in lowering parasitism rates on other islands, and may be considered for Andros (Baltz 1997). However, the cowbird population on Andros does not appear to have increased since the first recorded observations (Baltz 1995), so it may be premature to invest in such a program.

Lethal yellowing. Palm viability was a major factor influencing local population density of orioles. Between 2005 and 2009, we noted a significant decline in coconut palm health on NA due to lethal yellowing, leading to local declines in breeding oriole density. Continuing loss of palms on NA may increase competition for the remaining suitable nest sites or promote dispersal to new, potentially less favorable areas. Narvaez et al. (2006) reported that endemic Thrinax and Coccothrinax can host lethal yellowing without showing symptoms, providing a reservoir for future outbreaks and inhibiting efforts to combat the disease. Several resorts on NA have successfully inoculated coconut palms against infection, and local efforts to plant disease-resistant cultivars are underway (pers. obs.). Palm trees on MC and SA appear diseasefree at present, but remain vulnerable to spread of the phytoplasma from NA or introduction of a new phytoplasma.

Management suggestions. Because islands in the Caribbean have lost $88.7 \%$ of their native vegetation, the 148 remaining endemic bird species need careful management if they are to continue providing crucial ecosystem services such as seed dispersal, decomposition, and pollination (Şekercioğlu et al. 2004). Supporting $2.3 \%$ of the world's endemic plants and $2.9 \%$ of the world's endemic vertebrates in a proportionately small area (Şekercioğlu et al. 2004), management decisions in the Caribbean have important ramifications for global biodiversity. Although the focus of conservation should be protection of whole ecosystems rather than piecemeal strategies for separate species (Myers et al. 2000), comprehensive speciesfocused studies must inform habitat management decisions.

Small endemic populations of species such as Bahama Orioles may never have existed in large numbers (Baltz 1997), but are nonetheless an important source of diversity. Recent studies have resulted in taxonomic elevation to species status for the Bahama Oriole, Cuban Oriole (Icterus melanopsis), Puerto Rican Oriole (Icterus portoricensis), and Hispaniolan Oriole (Icterus dominicensis; Garrido et al. 2005, Price and Hayes 2009, Sturge et al. 2009, American Ornithologists' Union 2010). With $<300$ individuals remaining, Bahama Orioles may be the rarest bird species in the Bahamas and are facing the threat of extinction. Aggressive trapping programs to reduce the number of Shiny Cowbirds (Baltz 1997), planting of diseaseresistant palm cultivars, and conscientious management of coppice habitat may prevent the loss of this rare bird. Translocation of individuals to Abaco to reestablish the population recently lost 
there might prove more beneficial in the long term than intense cowbird removal, but translocation comprises a time- and energy-intensive action that would need extensive preparation and follow-up. Demographic data are urgently needed to develop a comprehensive action plan for the species (Hilton et al. 2005). Future study should also examine whether dependence on nonnative palms for nesting has created an ecological trap (Schlaepfer et al. 2002).

The juxtaposition of residential and agricultural nesting areas to suitable native habitats for foraging may be more important for Bahama Orioles than any other single factor. At all nest sites, we observed parents flying from their nests in anthropogenic habitat to nearby coppice to forage during most forays and, at two nests, family groups were observed in coppice several days after young had fledged. Because winter surveys also indicate oriole dependence on broadleaf habitat (Currie et al. 2005), coppice appears to be essential yearround for oriole survival. Pine forest habitat has tended to increase with human occupation whereas coppice habitat has decreased due to the effects of forest fires on ecological succession (Myers et al. 2004), resulting in limited patches of coppice interspersed throughout areas of anthropogenic habitat and pine forest. Coastal development has further exacerbated the loss of coppice (Wunderle and Waide 1993), and continues unabated on Andros (Thurston 2010). Coppice is also important for other resident, wintering, and migratory birds (Currie et al. 2005). Conservation efforts, therefore, should focus on preserving those areas of coppice that may be lost to future development, and pine forest should be managed so that succession to coppice is allowed to occur over time. Finally, because of the oriole's current dependence on anthropogenic habitat for nesting, education of Bahamians will be especially important in preserving the species.

\section{ACKNOWLEDGMENTS}

Funding was provided by the Insular Species Conservation Society, and by the Department of Earth and Biological Sciences at Loma Linda University. We thank E. Gren, S. and V. Myers, and K. Ingrey for help with field work in 2009. E. and C. Elmendorf, E. Gren, and F. Woolley kindly helped with field work in 2010. R. Riley (Bahamas National Trust) and E. Paul (Ornithological Council) assisted with obtaining permits. C. Forbes and A. Canestrari negotiated access for us to the Atlantic
Undersea Test and Evaluation Center on North Andros. Research was approved by the Loma Linda University Institutional Animal Care and Use Committee, and conducted under a Bahamas Ministry of the Environment Research Permit.

\section{LITERATURE CITED}

Allen, J. A. 1890. Description of a new species of Icterus from Andros Island, Bahamas. Auk 7: 343-346.

American Ornithologists' Union. 2010. Fifty-first supplement to the American Ornithologists' Union check-list of North American birds. Auk 127: 726744.

BALTZ, M. E. 1995. First records of Shiny Cowbird (Molothrus bonariensis) in the Bahama Archipelago. Auk 112: 1039-1041.

1996. The distribution and status of the Shiny Cowbird on Andros Island. Bahamas Journal of Science 3: 2-5.

- 1997. Status of the Black-cowled Oriole (Icterus dominicensis northropi) in the Bahamas. Department of Agriculture, Nassau, Bahamas.

Beck, M. J., And T. L. George. 2000. Song post and foraging site characteristics of breeding Varied Thrushes in northwestern California. Condor 102: 93-103.

BOARDMAN, R. 2006. The international politics of bird conservation: biodiversity, regionalism and global governance. Edward Elgar Publishing, Northampton, MA.

Brush, T., AND B. Y. Pleasants [online]. 2005. Altamira Oriole (Icterus gularis). In: The Birds of North America Online (A. Poole, ed.). Cornell Lab of Ornithology, Ithaca, NY. < http://bna.birds. cornell.edu/bna $>$ (16 March 2010).

CHILD, R. 1974. Coconuts. Longman Publishing Group, New York, NY.

CoHEN, J. 1988. Statistical power analysis for the behavioral sciences, 2 nd ed. Erlbaum Associates, Hillsdale, NJ.

Coulombe, G. L., D. C. Kesler, And A. Gouni. 2011. Agricultural coconut forest as habitat for the critically endangered Tuamotu Kingfisher (Todiramphus gambieri gertrudae). Auk 128: 283-292.

Currie, D., J. M. Wunderle, Jr., D. N. Ewert, M. R. Anderson, A. Davis, And J.Turner. 2005. Habitat distribution of birds wintering on Central Andros, The Bahamas: implications for management. Caribbean Journal of Science 41: 75-87.

Darbro, J. M., and L. C. Harrington. 2007. Avian defensive behavior and blood-feeding success of the West Nile vector mosquito, Culex pipiens. Behavioral Ecology 18: 750-757.

Donovan, T. M., C. J. Beardmore, D. N. Bonter, J. D. Brawn, R. J. Cooper, J. A. Fitzgerald, R. Ford, S. A. Gauthreaux, T. L. George, W. C. Hunter, T. E. Martin, J. Price, K. V. RosenberG, P. D. Vickery, AND T. B. Wigley. 2002. Priority research needs for the conservation of Neotropical migrant landbirds. Journal of Field Ornithology 73: 329-339.

Flood, N. J. [online] 2002. Scott's Oriole (Icterus parisorum). In: The birds of North America online 
(A. Poole, ed.). Cornell Lab of Ornithology, Ithaca, NY. < http://bna.birds.cornell.edu/bna> (16 March 2010).

—, J. D. Rising, And T. BRush [online]. 2002. Audubon's Oriole (Icterus graduacauda). In: The Birds of North America Online (A. Poole, ed.). Cornell Lab of Ornithology, Ithaca, NY. <http:// bna.birds.cornell.edu/bna> (16 March 2010).

Frankham, R., J. D. Ballou, and D. A. Briscoe. 2002. Introduction to conservation genetics. Cambridge University Press, Cambridge, UK.

Garrido, O. H., J. W. Wiley, and A. KirkCOnNell. 2005. The genus Icterus in the West Indies. Ornitologia Neotropical 16: 449-470.

Hayes, W. K., R. X. BARry, Z. McKenzie, And P. Barry. 2004. Grand Bahama's Brown-headed Nuthatch: a distinct and endangered species. Bahamas Journal of Science 12: 21-28.

Hilton, G. M, G. A. L. Gray, E. Fergus, S. M. Sanders, D. W. Gibbons, Q, Bloxam, C. Clubbe, AND M. IVIE (EDS.). 2005. Species Action Plan for the Montserrat Oriole Icterus oberi. Department of Agriculture, Montserrat.

Jaramillo, A., AND P. Burke. 1999. New world blackbirds: the Icterids. Princeton University Press, Princeton, NJ.

Johnston, R. F. 2001. Synanthropic birds of North America. In: Avian ecology and conservation in an urbanizing world (J. M. Marzluff, R. Bowman, and R. Donnelly, eds.), pp. 49-67. Kluwer Academy Publishers, Boston, MA.

Kamp, J., R. D. Sheldon, M. A. Koshkin, P. F. Donald, And R. Biedermann. 2009. Post-Soviet steppe management causes pronounced synanthropy in the globally threatened Sociable Lapwing Vanellus gregarious. Ibis 151: 452-463.

Karels, T. J., F. S. Dobson, H. S. Trevino, and A. L. SKIBIEL. 2008. The biogeography of avian extinctions on oceanic islands. Journal of Biogeography 35: 1106-1111.

Ligi, S., AND K. OMLand. 2007. Contrasting breeding strategies of two sympatric orioles: first documentation of double brooding by Orchard Orioles. Journal of Field Ornithology 78: 298-302.

Lloyd, J. D., AND G. L. Slater. 2011. Abundance and distribution of breeding birds in the pine forests of Grand Bahama, Bahamas. Journal of Caribbean Ornithology, in press.

Lothrup, H. D., B. Lothrop, AND W. K. Reisen. 2002. Nocturnal microhabitat distribution of adult Culex tarsalis (Diptera: Culicidae) impacts control effectiveness. Journal of Medical Entomology 39: 574-582.

Lund, U., AND C. Agostinelli [online]. 2011. Package "Circular." < http://cran.r-project.org/web/ packages/circular/circular.pdf > (23 March 2011).

Mertler, C. A., AND R. A. VAnnatTa. 2004. Advanced and multivariate statistical methods: practical application and interpretation, 3rd ed. Pyrczak Publishing, Los Angeles, CA.

Myers, N., R. A. Mittermeier, C. G. Mittermeier, G. A. B. dA FonsECA, AND J. KENT. 2000. Biodiversity hotspots for conservation priorities. Nature 403: 853-858.
Myers, R., D. Wade, And C. Bergh. 2004. Fire management assessment of the Caribbean pine (Pinus caribaea) forest ecosystems on Andros and Abaco Islands, Bahamas. Global Fire Initiative publication no. 2004-1, The Nature Conservancy, Arlington, VA.

NaKagawA, S. 2004. A farewell to Bonferroni: the problems of low statistical power and publication bias. Behavioral Ecology 15: 1044-1045.

Narvaez, M., I. Cordova, R. Orellana, N. A. HARRISON, AND C. OROPEZA. 2006. First report of a lethal yellowing phytoplasma in Thrinax radiate and Coccothrinax readii palms in the Yucatan Peninsula of Mexico. Plant Pathology 55: 292.

NATIONAL Audubon Society [online]. 2010. The Christmas Bird Count historical results. <http:// www.audubon.org/bird/cbc > (5 April 2010).

Paulay, G. 1994. Biodiversity on oceanic islands: its origin and extinction. American Zoology 34: 134144.

Price, M. R., AND W. K. HaYes. 2009. Conservation taxonomy of the Greater Antillean Oriole (Icterus dominicensis): diagnosable plumage variation among allopatric populations supports species status. Journal of Caribbean Ornithology 22: 19-25

Ricklefs, R., AND E. Bermingham. 2008. The West Indies as a laboratory of biogeography and evolution. Philosophical Transactions of the Royal Society B 363: 2393-2413.

Rising, J. D., AND N. J. FloOd [online]. 1998. Baltimore Oriole (Icterus galbula). In: The birds of North America online (A. Poole, ed.). Cornell Lab of Ornithology, Ithaca, NY. <http://bna.birds. cornell.edu/bna > (16 March 2010).

- AND P. L. WILliams [online]. 1999. Bullock's Oriole (Icterus bullockii). In: The Birds of North America Online (A. Poole, ed.). Cornell Lab of Ornithology, Ithaca, NY. <http://bna.birds.cornell.edu/bna> (16 March 2010).

Russell, E. M., Y. Yom-Tov, And E. GefFen. 2004. Extended parental care and delayed dispersal: northern, tropical, and southern passerines compared. Behavioral Ecology 15: 831-838.

SChaefer, V. H. 1976. Geographic variation in the placement and structure of oriole nests. Condor 78 : 443-448.

Schlaepfer, M. A., M. C. Runge, And P. W. Sherman. 2002. Ecological and evolutionary traps. Trends in Ecology and Evolution 17: 474-480.

Şekercioğlu, C. H., G. C. Dailey, and P. R. Ehrlich. 2004. Ecosystem consequences of bird declines. Proceedings of the National Academy of Sciences USA 101: 18042-18047.

SKuTCH, A. F. 1996. Orioles, blackbirds and their kin. University of Arizona Press, Tucson, AZ.

STEADMAN, D. W. 2006. Extinction and biogeography of tropical Pacific birds. University of Chicago Press, Chicago, IL.

Sturge, R. J., F. Jacobsen, B. B. Rosensteel, R. J. NEALE, AND K. E. OMLAND. 2009. Colonization of South America from Caribbean islands confirmed by molecular phylogeny with increased taxon sampling. Condor 111: 575-579.

Tallamy, D. W. 2004. Do alien plants reduce insect biomass? Conservation Biology 18: 1689-1692. 
Thurston, G. [online]. 2010. South Andros farm road progresses. <http://www.bahamaslocal.com/news item/8010/South_Andros_farm_road_progresses. htm > (16 March 2010).

WERNER, S. M., S. J. HeJL, AND T. BRUSH. 2007. Breeding ecology of the Altamira Oriole in the lower Rio Grande Valley, Texas. Condor 109: 907-919.

White, A. W. 1998. A birder's guide to the Bahama Islands (including Turks and Caicos). American Birding Association, Inc., Colorado Springs, CO.

WILEY, J. W. 1985. Shiny Cowbird parasitism in two avian communities in Puerto Rico. Condor 87: 165-176.
Woods, C. A., AND F. E. Sergile. 2001. Biogeography of the West Indies: patterns and perspectives, 2nd ed. CRC Press, Boca Raton, FL.

Wunderle, J. M., Jr., J. E. Mercado, B. Parresol, and E. TERrANOVA. 2004. Spatial ecology of Puerto Rican boas (Epicrates inornatus) in a hurricane impacted forest. Biotropica 36: 555-571.

— tering Nearctic migrants in the Bahamas and Greater Antilles. Condor 95: 904-933.

ZAR, J. H. 1996. Biostatistical analysis, 3rd ed. Prentice Hall, Upper Saddle River, NJ. 